\title{
Development and Characterization of 430L Matrix Composites Gradient Materials
}

\author{
Elisa Maria Ruiz-Navas*, Elena Gordo, Ricardo García
}

\author{
Department of Materials Science and Metallurgical Engineering \\ Universidad Carlos III de Madrid \\ Avda Universidad 30. E-28911 Leganés
}

Received: March 10, 2003; Revised: November 22, 2004

\begin{abstract}
This paper deals with a new concept that is Functionally Gradient Materials (FGM). The materials developed in this work are constituted by a 430L matrix core and composite materials with this matrix and gradient concentration with $\mathrm{NbC}$ reinforcement, from the core to the surface, through different steps. Composite powders of different content in $\mathrm{NbC}$ were produced through high energy milling in order to obtain the gradient composition. The morphology and microhardness of these powders were characterised and subsequently were processed through conventional $\mathrm{P} / \mathrm{M}$ techniques, pressing and sintering. The materials obtained show improved wear behaviour.
\end{abstract}

Keywords: functionally graded materials, 430L, powder metallurgy

\section{Introduction}

Many components are subjected to non-uniform mechanical, thermal or chemical requirements distributed through its section. In particular, a soft and tough core bonded to a hard and wear resistant surface is usually demanded. Consequently, there exists great deal of applications impossible to solve with a unique composition where the optimal structure would consist of a toughness metal core and a high temperature, corrosion and wear resistant ceramic surface. However, if a ceramic layer would be joined to the metallic core the structure would be highly susceptible of thermal cycling, leading to thermal stresses and fatigue in the interface, which would break the component. A material designed with a soft transition from the metallic core to the ceramic surface would avoid this thermal and thermomechanical stresses.

The Functionally Gradient Materials (FGM) try to cover this gap, showing the possibility to combine two ore more properties avoiding the disadvantages of a simple bonding between them ${ }^{1}$. The FGM consist of materials which composition and structure change gradually in their volume, producing changes also graduated in their properties.

There exist several methods available nowadays for the FGM production: Sequential Slip Casting ${ }^{2}$, Thermal Spraying 3 , Physical Vapour Deposition (PVD), Chemical Vapour Deposition (CVD) ${ }^{4}$ and Laser claddding ${ }^{5}$ are the more significant.

However, FGM can be processed by Powder Metallurgy (PM) following the conventional techniques by wet and dry routes. P/M offers more advantages by means of the lower costs, higher raw materials availability, simpler processing equipment, lower energy consumption and shorter processing times. In a global sense the higher advantages in P/M materials can be numbered as higher composition uniformity leading to segregation absence and a finer and more uniform distribution in the second phases as precipitates and carbides. It is especially important when the material is constituted by two or more bonded phases, matrix and reinforcement, trying to combine the most interesting properties of each one of them, in a composite material. PM offers the advantage, in front of other conventional techniques, of the possibility to obtain a composite material with higher content of reinforcement. Besides, another advantage of PM is showed in this work as the possibility of changing the composition as a function of

*e-mail: emruiz@ing.uc3m.es

Article presented at the XV CBECIMAT, Natal - RN, November/2002 the requirements and with the aim of a FGM obtaining.

The iron or steel MMC's are being studied since the 70's, combining the toughness, ductility and low friction coefficient of the metal matrix with the hardness, strength and wear resistance of the ceramic reinforcement. In the last years the $\mathrm{NbC}$ and $\mathrm{TaC}$ are being employed as reinforcement to improve the wear resistance ${ }^{6}$.

\section{Experimental Procedure}

The main objective of this work was the obtaining of a functionally graded material through powder metallurgy techniques.

A 430L stainless steel powder, provided by Coldstream, was employed as matrix material. As reinforcement, $\mathrm{NbC}$ powder from Goodfellow Cambridge Ltd, was used. The elemental composition can be seen in Table 1 .

The first step for the samples production was the obtaining of the reinforced material. For this purpose it was carried out a milling stage in a high-energy planetary ball mill for 40 hours at $180 \mathrm{rpm}$, with a load of $1 / 3$ of balls $1 / 3$ of material and $1 / 3$ of air in a stainless steel container. Several millings were carried out in order to obtain the different percentages $(2.5,5,8 \%$ vol.) of reinforcement in the high speed steel matrix. A complex characterisation of these powders was achieved in their morphology, reinforcement distribution and microhardness.

The consecution of the gradient materials was developed through the fabrication of different samples as can be seen in Figure 1.

The samples were produced with a graded composition through the building of different layers with changed and growing content in $\mathrm{NbC}$. Three kinds of samples were produced: a base one with an only 430L composition (named A), two layered ones with the lower layer of $430 \mathrm{~L}$ base material and the upper layer of 430 reinforced with 2, 5, 5 or $8 \%$ of $\mathrm{NbC}$ (named B2, B5 and B8 respectively) and the third kind a multilayered sample constituted for 4 layers of $430 \mathrm{~L}$ base material and a growing content in $\mathrm{NbC}$ from the bottom to the top (named C).

The samples were consolidated though conventional PM techniques: uniaxial pressing and sintering. Previous to these steps, and owed to the high energy involved in the milling, it was necessary to realise an annealing to the composite powder in order to be able to 
Table 1. Elemental composition of AISI 430L stainless steel and NbC powder.

\begin{tabular}{cccccccccc}
\hline Powder & $\mathrm{C}$ & $\mathrm{Fe}$ & $\mathrm{Mn}$ & $\mathrm{Cr}$ & $\mathrm{Si}$ & $\mathrm{O}$ & $\mathrm{Ta}$ & $\mathrm{Nb}$ & $\mathrm{Ti}$ \\
\hline AISI 430L & 0.018 & $\mathrm{Bal}$ & 0.180 & 16.85 & 1.150 & 0.279 & - & - & - \\
$\mathrm{NbC}$ & 11.2 & 0.08 & - & - & 0.04 & 0.392 & 0.15 & 88.23 & 0.1 \\
\hline
\end{tabular}

deform it during the pressing step. The conditions for this annealing were determined though DTA (Differential Thermal Analysis). It was realised in argon at $450{ }^{\circ} \mathrm{C}$ for 1 hour with a heating rate of $5 \mathrm{~K} / \mathrm{min}$.

The compaction step was carried out in a uniaxial press with floating matrix; zinc stearate was used as the lubrication. The powders with different content in $\mathrm{NbC}$ reinforcement were deposited in layers as shown above (Figure 1) and were pressed in an only step at $600 \mathrm{MPa}$ instead of using a precompaction of the individual layers ${ }^{7}$. After pressing, the sintering was carried out in argon at $1250{ }^{\circ} \mathrm{C}$ for 30 minutes.

Finally, the samples were characterised in their microhardness profile and wear behaviour. The wear tests were carried out in a pin-on-disc equipment and following the ASTM G99 standard. The conditions employed are presented in Table 2.

\section{Results and Discussion}

The first results can be analysed though the powder characterisation. After the milling operation three different powders were obtained as can be seen in Figure 2.The main results we can observe in this figure are the morphological as well as the size evolution suffered from the powder. In Figure 2a we can see the raw material, the 430 powder as received. It can be seen the surface roughness as well as the rounded shapes typical in a water atomised powder. Its behaviour during milling is that of a ductile material, obviously not as ductile as plain iron but with a considerable tendency to deformation in the firsts stages of the process.

The 430L raw powder has been milled with different quantities of $\mathrm{NbC}$ reinforcement and three different composite powders have been obtained. From the Figure 2 it is clear that the morphology of the raw powder (Figure 2a) changes mainly losing its rounded and soft shapes because of the milling operation. This way, as the time goes the high energy milling provokes the deformation, flattening and welding of the particles. The higher is the energy involved in the process the earlier it is produced. This energy can be understood in terms of time, speed or by other mechanism. In this case it is evident the influence of the reinforcement.

This way, it can also be observed how an increase in the reinforcement content promotes heavier changes in the powder particles, providing more flattened shapes and smaller sizes when the reinforcement content is raised. These $\mathrm{NbC}$ hard particles absorb the milling energy in their fracture instead of deformation but also increase the deformation level in the softer particles. They are also trapped between the $430 \mathrm{~L}$ particles working as bonding points helping to the welding stage. This mechanism has been widely explained with several materials ${ }^{8,9}$.

Then, if we compare the $430+5 \% \mathrm{NbC}$ composite powder with the $430+2.5 \% \mathrm{NbC}$ one (Figure $2 \mathrm{a}$ and $2 \mathrm{~b}$ ) we can see that the higher the percentage of $\mathrm{NbC}$ the more is the deformation of the powder, leading to flattened and flakes-like particles. The same phenomenon is produced when an $8 \%$ of $\mathrm{NbC}$ is added, and rounded and equiaxed, as well as with smaller size, particles are obtained earlier because of the acceleration of the process described above, getting the final stage.

Regarding the microhardness of the powders, Figure 3 shows the results obtained for this property. We can see in this figure the increasing of the powder microhardness, mainly if we compare the value corresponding to the raw material $430 \mathrm{~L}$, highly ductile, with

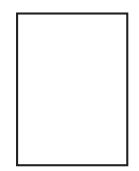

A

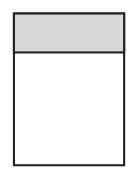

B2

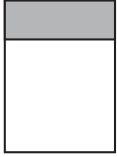

B5

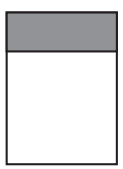

B8

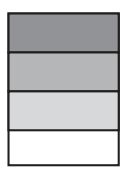

$\mathrm{C}$

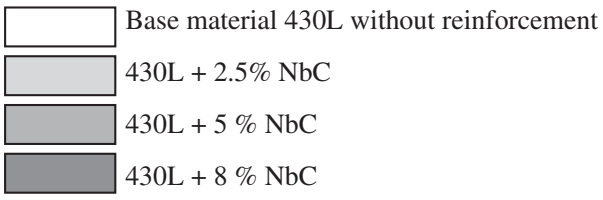

Figure 1. Scheme of the samples fabrication.

Table 2. Pin-on-disc test conditions.

\begin{tabular}{ll}
\hline Radius & $5 \mathrm{~mm}$ \\
\hline Pin & Ball of $\mathrm{Al}_{2} \mathrm{O}_{3}$. Hardness $>2500 \mathrm{HV}, \phi=6 \mathrm{~mm}$ \\
Load & $10 \mathrm{~N}$ \\
Sliding Distance & $1000 \mathrm{~m}$ \\
Sliding speed & $0,25 \mathrm{~m} / \mathrm{s}$ \\
Temperature & Room Temp \\
Moisture & $<30 \%$ \\
\hline
\end{tabular}

the values for the composite powders after the milling.

The most important growth from $145 \mathrm{HV}$ to $310 \mathrm{HV}$, more than the double, is caused by the milling time instead of the $\mathrm{NbC}$ content. The influence of this last parameter is hardly appreciated, only from $310 \mathrm{HV}$ to $320 \mathrm{HV}$ when the reinforcement has been increased from 2.5 to $8 \%$, what confirms its lower influence.

Once obtained the samples their microhardness profiles were analysed in order to study the bonding between layers as well as the continuity in that property. The results for samples B2, B5 B8 and C can be seen in Figures 4 and 5 respectively.

As can be perfectly seen in this figure the expected hardness profile is not obtained in B5 samples since a lowering or reduction of hardness in the surface is observed. B2 and B8 samples show the expected profile. However it was expected to obtain higher values of hardness near the surface in samples B8 owed to their higher carbide content.

It has to be pointed that in B5 type samples the hardness is maintained in the interface showing a good bonding between the composite layer and the substrate. The same behaviour, although lower than it was supposed, can be seen in B2 and B8 samples where the hardness is softly diminished. This progressive reduction is more related to the carbide content than to the layers bonding. Otherwise there would be a low hardness gap between them. The best results have been obtained for B2 samples, which surface hardness shows values till $250 \mathrm{HV}_{0.01}$ decreasing with the distance till $90 \mathrm{HV}_{0.01}$ near the base material hardness.

Despite these results it can be also observed that, although the hardness profile has a good evolution from the point of view of layers bonding, in B2 and B5 samples the hardness values are lower than they were expected in the surface. The differences between them can only be explained through the surface powders morphology as well as the size distribution. These characteristics lead to high porosity at 

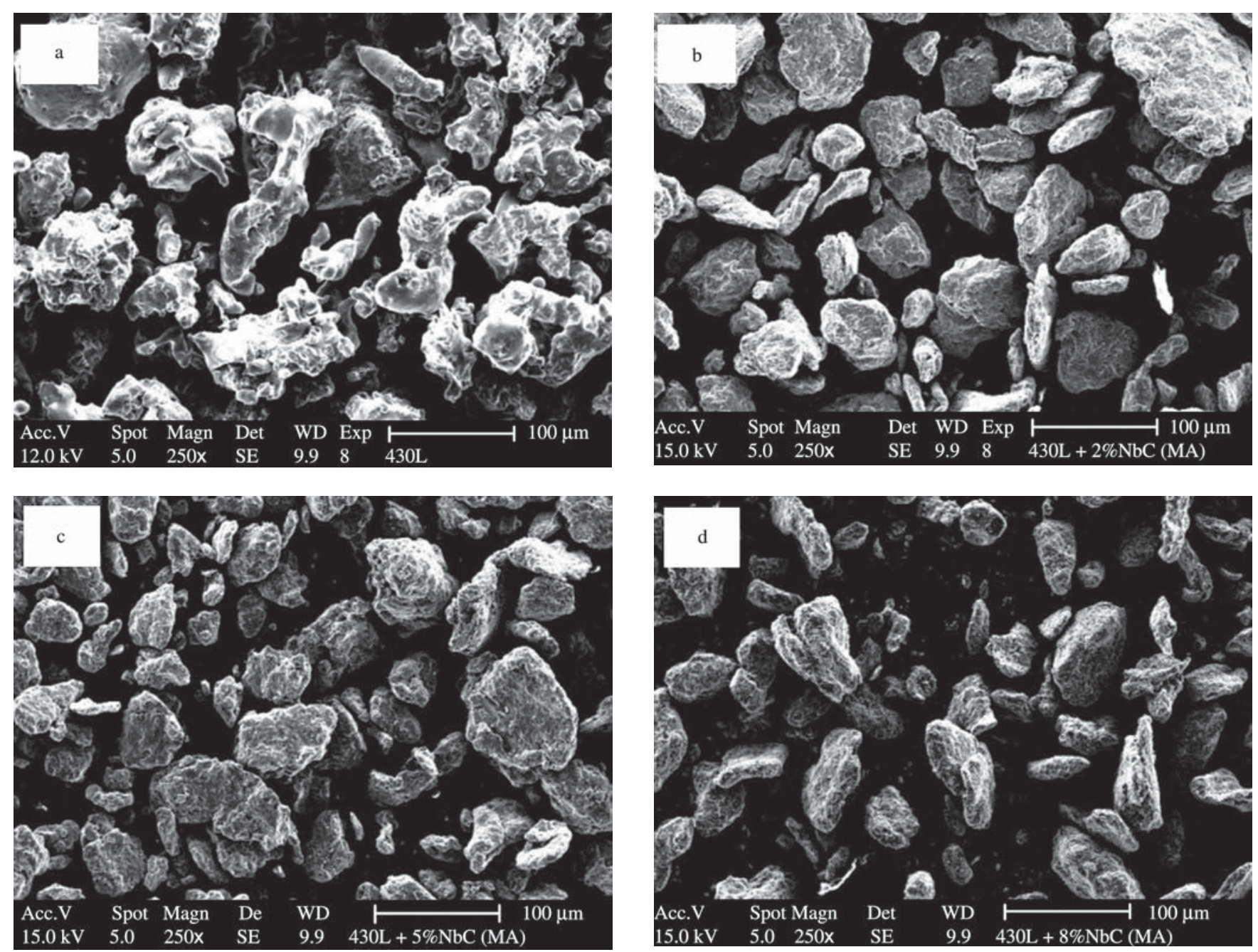

Figure 2. a) 430L Raw powder; b) 430 reinforced with $2.5 \%$ of $\mathrm{NbC}$; c) $5 \%$ of $\mathrm{NbC}$; d) $8 \%$ of $\mathrm{NbC}$

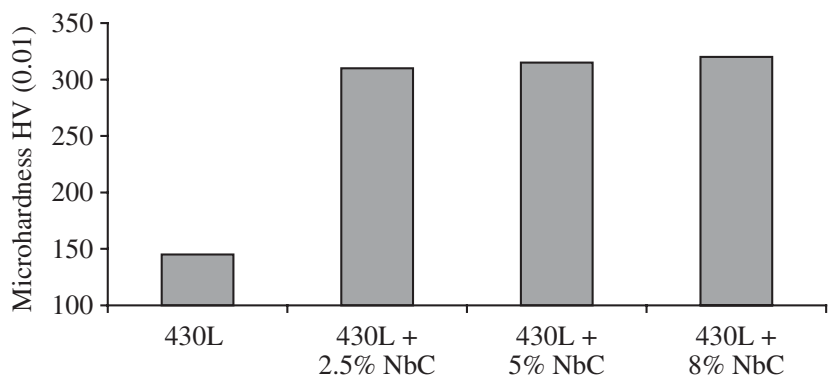

Figure 3. Microhardness of the powders.

the surface of the samples which, coming from the pressing stages, is maintained and not eliminated during the sintering step.

This surface porosity, characteristic in B5 and B8 samples, and responsible of the low hardness, was also observed in samples $\mathrm{C}$ which microhardness profile shows a great fall in the surface where the higher reinforcement content is employed.

It can be perfectly seen how they show a growth and a maximum value, near $350 \mathrm{HV}_{0.01}$, in the layer corresponding to the $5 \%$ of $\mathrm{NbC}$ reinforcement. It can also be seen the good bonding between layers through the soft and progressive decreasing of hardness, from the 5\% of $\mathrm{NbC}$ to $2.5 \% \mathrm{NbC}$ and to the base material.

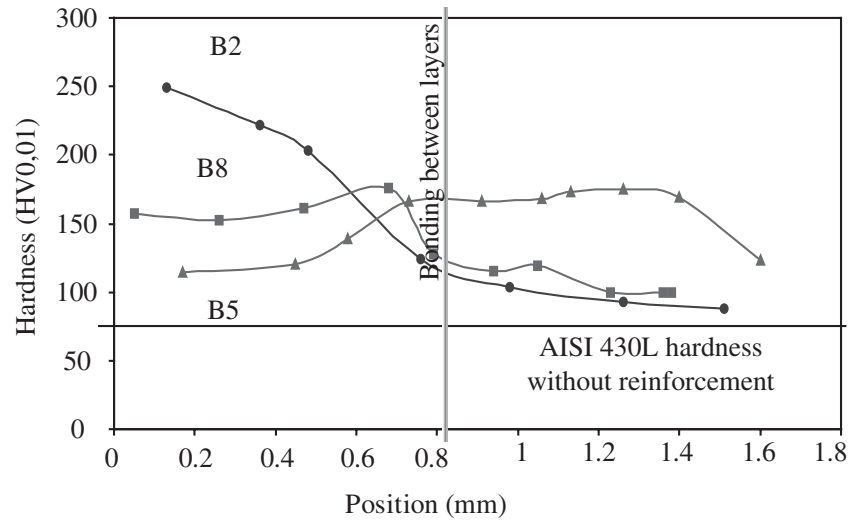

Figure 4. B2, B5 and B8 samples microhardness profile.

This way, the lack of good bonding between surface particles, probably due to their hardness, morphology and size distribution, results in a high level of porosity what is finally manifested by the fall of the surface hardness. However, once this is avoided, going deeply in the sample, a homogeneous growth in the hardness is obtained owed to the layers, hardness that softly decreases with the reinforcement content.

Finally, the wear behaviour of these samples was evaluated by 
means of the pin-on-disc test. Figure 6 shows the friction coefficient of the different materials tested.

As it can be seen all the materials, despite of the different percentage of reinforcement, show a similar value of friction coefficient. However, it can be seen that the higher the $\mathrm{NbC}$ content the faster it is stabilised as well as lower is the scattering of the values during sliding. It is clear with the $430 \mathrm{~L}$ base material without reinforcement which friction coefficient is not stabilised till the last 200 meters and which dispersion is the higher, showing a scattering of the friction coefficient three times higher than the values obtained for the reinforced materials. This behaviour could be caused by the high level of surface porosity. This porosity is closed during the test what finally stabilises the contact between material and countermaterial.

The tribological behaviour of the different materials has been also evaluated through the wear coefficient and the ball weight loss. The results of these properties are shown in Figure 7.

Both elements, material and countermaterial, show the same tendency: the improvement in their wear behaviour as the reinforcement grows. One of the most important reasons that justify the manu-

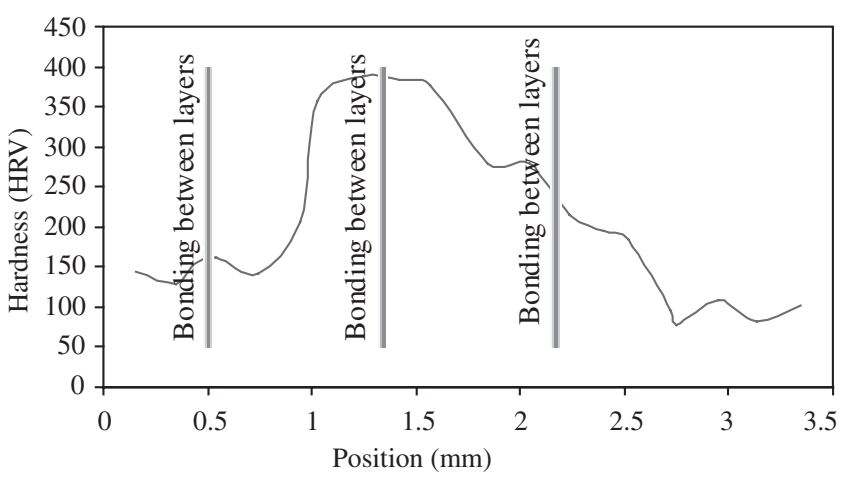

Figure 5. C samples microhardness profile.

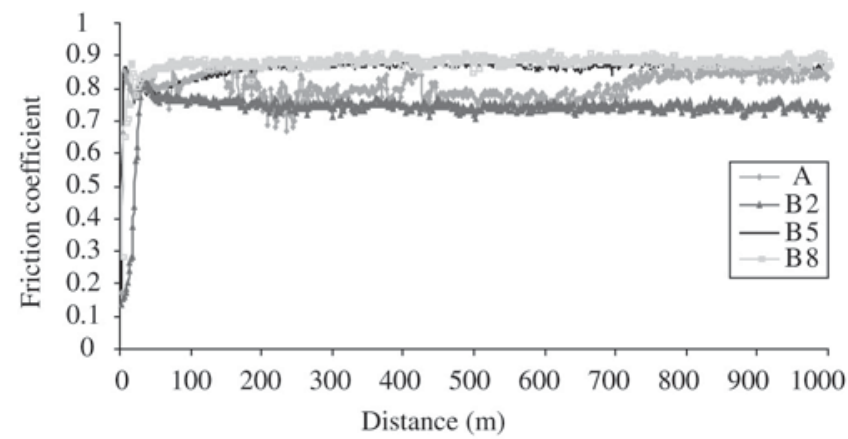

Figure 6. Friction coefficient.

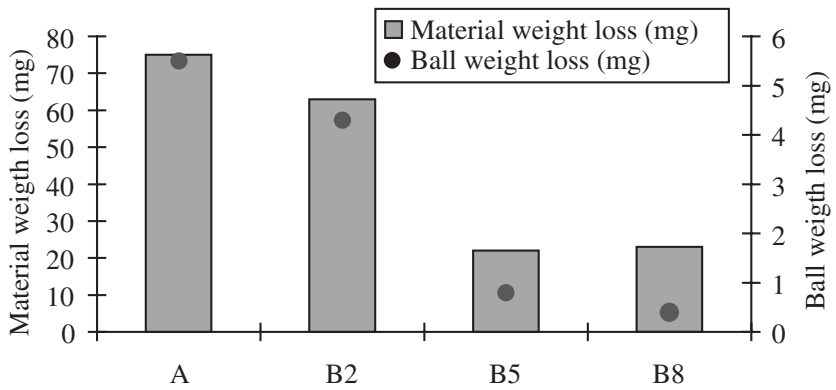

Figure 7. Material and ball wear constant. facturing of composite materials and one of the aims of this work is the improvement of the base material properties. This objective has been realised by means of the FGM concept, by the employment of a gradient and growing content in $\mathrm{NbC}$.

But we can also observe in this figure that the wear of the ball, analysed through the weight loss, is lower when the wear in the material studied is reduced. We can affirm that there is a great improvement in the wear behaviour of the materials, first of all when the 430 L base material is reinforced with a $2.5 \%$ and this improvement grows when a 5 and an $8 \%$ of $\mathrm{NbC}$ is added. Finally, we can also affirm that the improvement is obtained in the tribological system since the wear in the alumina ball is also reduced.

These results are coherent with the obtained for the friction coefficient where the high dispersion shown for the material without reinforcement (A samples) reveals its higher tendency to the formation of debris. This way a typical three-bodies-wear mechanism provokes higher abrasion and wear both in the material and countermaterial, the ball.

\section{Conclusions}

The gradient materials have been successfully obtained. However surface hardness must be improved. The results, lower than expected, are associated to the samples production. An optimised powder, in size and shape, by the milling process and a sintering step in vacuum instead of argon will promote a diminution in the surface porosity.

The employment of the FGM concept, by means of a multilayered material, and different composite powders allows a great improvement in the wear behaviour. This benefit has been obtained not only in the studied material but also in the ball

The good adhesion and mechanical bonding between matrix and reinforcement, provided by the high energy milling in the powder production, is also manifested in these results.

These promising results constitute a set point to obtain tailored materials, through simple processing techniques as powder metallurgy, and with the saving of raw materials derived from the employment of the proposed method.

\section{References}

1. Neubrand A, Rödel J. Gradient Materials: An overview of a novel concept. Z. fur Metallkunde. 1997; 5(88):358-371.

2. Moya JS, Sánchez-Herencia JA, Requena. J, Moreno R. Functionally gradient ceramics by sequential slip casting. Materials Letters. 1992; 14:333-335.

3. Musil J, Fiala, J. Plasma spraying deposition of graded metal-ceramic coatings. Surface and Coating Technology. 1992; 52:211-220.

4. Sun D C, Yiang EY, Liu Ming S, Lin C: Fe-N gradient thin films prepared by facing targets sputtering. Journal of Physics. D: Applied Physics. 1995; 28:4-6.

5. Jasim KM, Rawlings RD, West DRF. Characterization of plasma-sprayed layers of fully yttria-stabilized zirconia modified by laser sealing. Journal of Material Science. 1993; 43(1-4):2820-2826

6. Gordo E, Velasco F, Antón N, Torralba JM. Wear mechanism in high speed steel reinforced with (NbC) and (TaC) pMCs. Wear. 2000; 239:251259.

7. Rhodes NA, Wood JV, Moon JR. Some aspects of diffusion in mixtures of tool steel powders and iron powders. Powder Metallurgy. 2000; 43:157-162.

8. Fogagnolo JB, Robert MH, Torralba JM. In: Dobrzanski L.A, editor. The effects of the presence of reinforcement particles on the mechanical milling of aluminium AA6061 matrix composite powder alloy. Proceedings of the Achievements in Mechanical and Materials Engineering; 2000 Oct; Poland: Polish Academy of Science; 2000. p.183-186.

9. Fogagnolo JB, Ruiz-Navas EM, Robert MH, Torralba JM. 6061 Al reinforced with silicon nitride particles processed by mechanical milling. Scripta Materiali, 2002; 47:243-248. 